\title{
СОСТАВ СМОЛЫ, ОБРАЗУЮЩЕИСЯ ПРИ ПРОИЗВОДСТВЕ ТЕРМОБИТУМА ИЗ СЛАНЦА-КУКЕРСИТА
}

В процессе производства термобитума из обогащенного кукерсита (керогена-70) на сланцеперерабатывающем комбинате «Сланцы» в качестве побочного продукта образуется дистиллят, несколько отличающнйся по составу как от промышленной слан цевой смолы, так и от смолы лабораторного полукоксования кукерсита.

В отличие от ранее применявшейся технологии [1] в настоящее время холодный кероген подается в нагретый до $200^{\circ} \mathrm{C}$ реактор, затем температуру в течение $3-5$ ч поднимают до $400^{\circ}$ и выдерживают ее на этом уровне еще $1-1,5$ ч. Выход продуктов битуминизации на кероген-70: термобитума (включая минеральную массу исходного концентрата) - 81,0\%, дистиллята (смолы) - 9,9\%, воды $-3,4 \%$, газа и потерь $5,7 \%$. Выход термобитума близок к максимально возможному [2-4].

Дистиллят битуминизации составляет около четверти потенциала смолы в керогене и представляет собой выкипающую примерно до $400^{\circ}$ фракцию смолы частичного термического разложения кукерсита. Сведения о составе этой смолы могут оказаться полезными для выяснения некоторых сторон механизма термического разложения керогена, а поскольку дистиллят битуминизации - это промышленный продукт, то знание его состава является необходимой предпосылкой обоснованного выбора путей практического использования указанной разновидности сланцевой смолы.

\section{Эксперимент и результаты}

С целью получить сравнительные данные было проведено лабораторное полукоксование (ГОСТ 3168-53) керогена кукерсита и термобитума производства комбината «Сланцы». Выход продуктов термолиза при битуминизации керогена и полукоксовании термобитума и керогена в пересчете на органическую массу исходного концентрата сланца приведен в табл. 1 .

Из представленных данных явствует, что при термическом разложении керогена в два этапа (битуминизация и полукоксование термобитума) выход смолы несколько ниже, а выход газа, воды и полукокса выше, чем в случае полукоксования при стандартном режиме нагрева. Это согласуется с представлениями о протекании на стадии образования термобитума комплекса реакций термостабилизации керогена, обусловливающих перераспределение вещества в пользу несмоляных продуктов $\left[{ }^{5,6}\right.$. Указанное явление, очевидно, имеет место также в условиях промышленного процесса битуминизации. 


\begin{abstract}
Выход продуктов термического разложения при битуминизации керогена кукерсита $(A)$ и полукоксовании термобитума $($ Б) и керогена $(B)$ (в пересчете на исходный кероген)
\end{abstract}

\begin{tabular}{l|r|r|r|c}
\hline \multicolumn{1}{c|}{ Продукт } & $A$ & E & $A+5$ & $B$ \\
\hline Смола & 14,2 & 44,3 & 58,5 & 65,1 \\
Вода разложения & 4,9 & 1,6 & 6,5 & 5,0 \\
Термобитум & 72,8 & $\overline{17,2}$ & $\overline{17,2}$ & 16,2 \\
Полукокс & $\overline{8,1}$ & 9,7 & 17,8 & 13,7 \\
Газ + потери & 100,0 & 72,8 & 100,0 & 100,0 \\
\hline \multicolumn{1}{c}{ Всего } & & & &
\end{tabular}

Состав обесфеноленной смолы и фенолов, извлеченных из смолы битуминизации 10\%-ным раствором гидроокиси натрия при двукратном избытке щелочи, исследовали с использованием методов тонкослойной (для предварительного разделения смеси на групповые компоненты) и газовой хроматографий (для анализа выделенных групп соединений). Препаративное разделение в тонком слое проводили по методике $\left.{ }^{7}\right]$ на силикагеле Л100/250 $\mu$ (Чехословакия); в случае смолы в качестве элюента применяли $\boldsymbol{t}$-гексан, в случае фенолов - смесь хлороформа и этилацетата $(3: 1)$. Газохроматографический анализ проводили на «Хром-4» с пламенно-ионизационным детектором в условиях программирования температуры, газом-носителем служил гелий.

Таблица 2

Сравнительная характеристика смолы битуминизации керогена кукерсита $(A)$ и выкипающей до $420^{\circ} \mathrm{C}$ фракции смолы полукоксования сланца (Б)

\begin{tabular}{l|l|l} 
Показатели & A & Б
\end{tabular}

Плотность $\mathrm{Q}_{20}^{20}$

Показатель преломления $n_{D}^{20}$

$0,916 \quad 0,929$

Фракционный состав, об. \%:

$1,4952 \quad 1,5096$

выкипает до $200^{\circ}$

до $200^{\circ}$
$\Rightarrow 250^{\circ}$
" $300^{\circ}$
" $350^{\circ}$

Элементный состав, вес. \%:

углерод

водород

гетеро-атомы (по разности)

Групповой химический состав:

неароматические углеводороды

моноциклические ароматические углеводороды

полициклические ароматические углеводороды

нейтральные кислородные соединения

фенолы

$\begin{array}{ll}25 & 23 \\ 42 & 38 \\ 61 & 56 \\ 78 & 70\end{array}$

$82,0 \quad 80,8$

$10,9 \quad 10,7$

$\begin{array}{ll}7,1 & 8,5\end{array}$

Результаты анализа дистиллята битуминизации представлены в табл. 2. Для сравнения приведены также данные о выкипающей до $420^{\circ}$ (760 мм рт. ст.) фракции смолы полукоксования сланца. Смола битуминизации по физическим показателям близка к выкипающей до $420^{\circ}$ части 
смолы полукоксования (отличаясь, следовательно, от суммарной смолы меньшей плотностью и облегченным фракционным составом), но по группор צу химическому составу заметно отличается от нее.

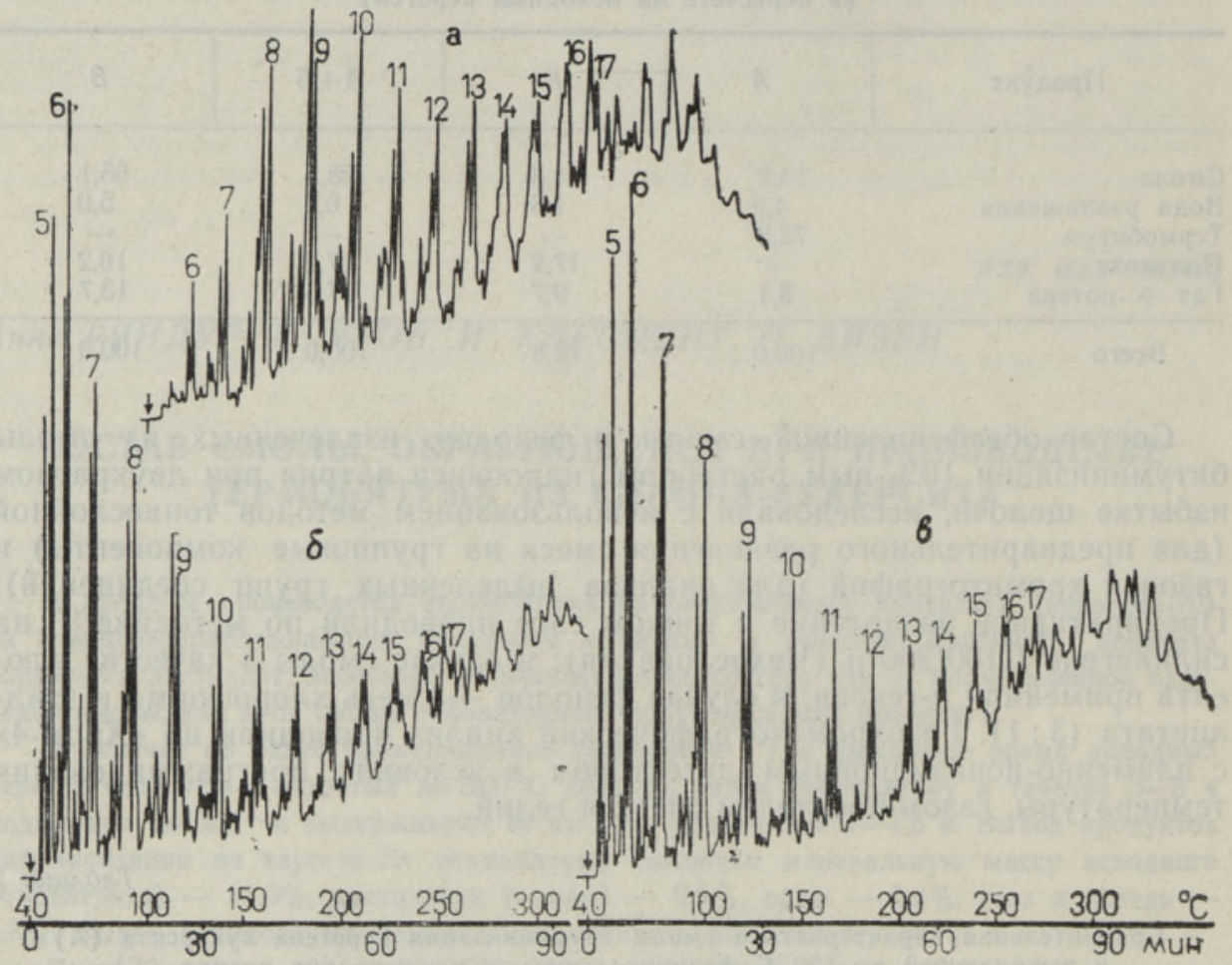

Рис. 1. Хроматограммы суммарных смол битуминизацин $(a)$ и полукоксования (б) кукерсита и смолы полукоксования термобитума $(8)$.

5-17 - число атомов углерода в молекуле соответствующего пику $\boldsymbol{H}$-алкана.

Колонка: $6 \%$ апиезона $L$ на хромосорбе $P$ (снланизир.), $6 \mu \times 3 \mathrm{M \mu}$.

На рис. 1 приведены хроматограммы смол битуминизации керогена и полукоксования термобитума и керогена. Судя по хроматограммам, две последние смолы относительно мало различаются между собой, однако в смоле полукоксования термобитума отсутствует острый максимум отношения $H$-1-олефин : $\boldsymbol{H}$-парафин при $\mathrm{C}_{9}$. Что касается смолы битуминизации, то она заметно отличается от смолы, образующейся при полукоксовании, низким содержанием алифатических углеводородов $\mathrm{C}_{5}-\mathrm{C}_{7}$, а также значительно меньшей по сравнению с последующими гомологами концентрацией $\boldsymbol{H}$-алканов $\mathrm{C}_{8}$ и $\mathrm{C}_{9}$.

Различие смол битуминизации и полукоксования кукерсита выступает более отчетливо при газохроматографическом анализе их групповых компонентов.

Неароматические углеводороды смолы битуминизации представлены в основном насыщенными и непредельными соединениями нормального строения (рис. 2). Несмотря на медленный нагрев и относительно низкую температуру, дистиллят битуминизации содержит по сравнению со смолой полукоксования больше $H$-алкенов. Это преимущественно 1-олефины, хотя здесь гораздо выше обычного относительная концентрация 2-олефинов и олефинов с двойной связью, расположенной ближе к середине цепи. 
Моноциклические ароматические углеводороды битуминизационной смолы отличаются от соответствующей фракции смолы полукоксования наличием большего количества низкокипящих соединений $\left(\mathrm{C}_{7}-\mathrm{C}_{12}\right)$. Характерной чертой полициклических ароматических углеводородов является очень низкая концентрация нафталина и его простейших алкилпроизводных; основная масса вещества приходится здесь на трехъядерные и более сложные структуры.

Несмотря на некоторые различия в концентрации отдельных индивидуальных соединений, нейтральные кислородные соединения рассматриваемых смол сходны. Интерес представляет преобладание алифатических кетонов нормального строения с нечетным числом атомов углерода в молекуле над соседними гомологами в области $\mathrm{C}_{9}-\mathrm{C}_{13}$ для $н$-алканонов-2 и в области $\mathrm{C}_{13}-\mathrm{C}_{17}$ для $\boldsymbol{H}$-алканонов с карбонильной группой в средней части цепи (рис. 3). Однако указанное явление обнаруживается не во всех смолах термического разложения кукерсита.

Фенолы смолы битуминизации (рис. 4) содержат примерно в 1,5 раза больше 5- $\mu$-алкилпро-

изводных резорцина по сравнению с фенолами смолы полукоксования (по данным тонкослойной хроматографии соответственно 47 и $30 \%$ от суммарных фенолов) и характеризуются очень низкой концентрацией простейших одноатомных фенолов при сравнительно близком общем содержании монофенолов в суммарных фенолах (соответственно 34 и $39 \%$ ). Подавляющая часть

Рис. 3. Хроматограмма фракции нейтральных кислородных соедннений смолы битуминизации кукерсита.

6-17 - число атомов углерода в молекуле соответствующего пику $\mu$-алканона-2; $11-17$ - число атомов углерода в молекуле соответствующего пику пой в средней части цепи. Колонка: $12 \%$ полиэтиленгликоль-сукцината на целите 545,2 м $\times 3$ мм.

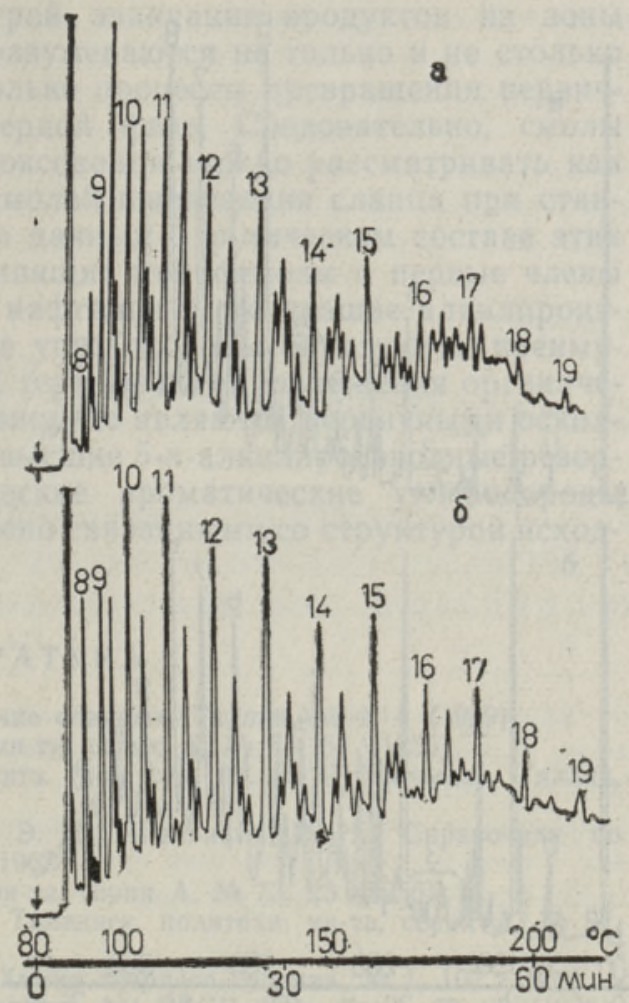

Рис. 2. Хроматограммы фракции неароматических углеводородов смол битуминизацип (a) и полукоксования (б) кукерсита.

$8-19$ - число атомов углерода в молекуле соответствующего пику н-алкана.

Колонка: $12 \%$ полиэтиленгликоля 40000 на хромосорбе $W, 6 м \times 3 \mu$.

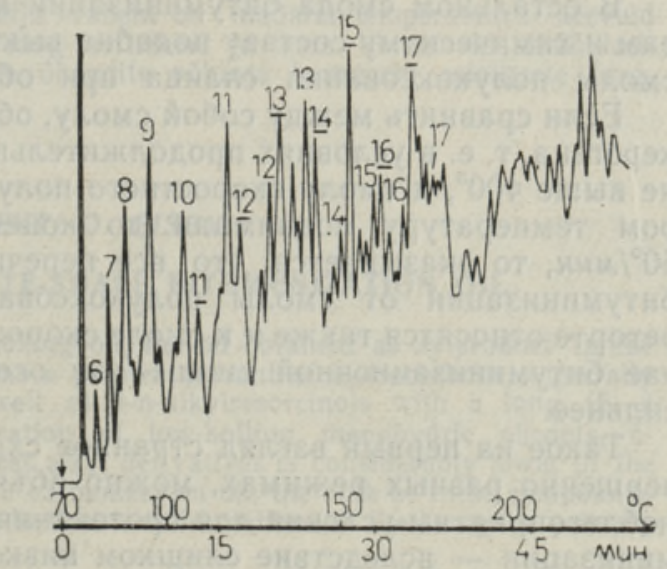




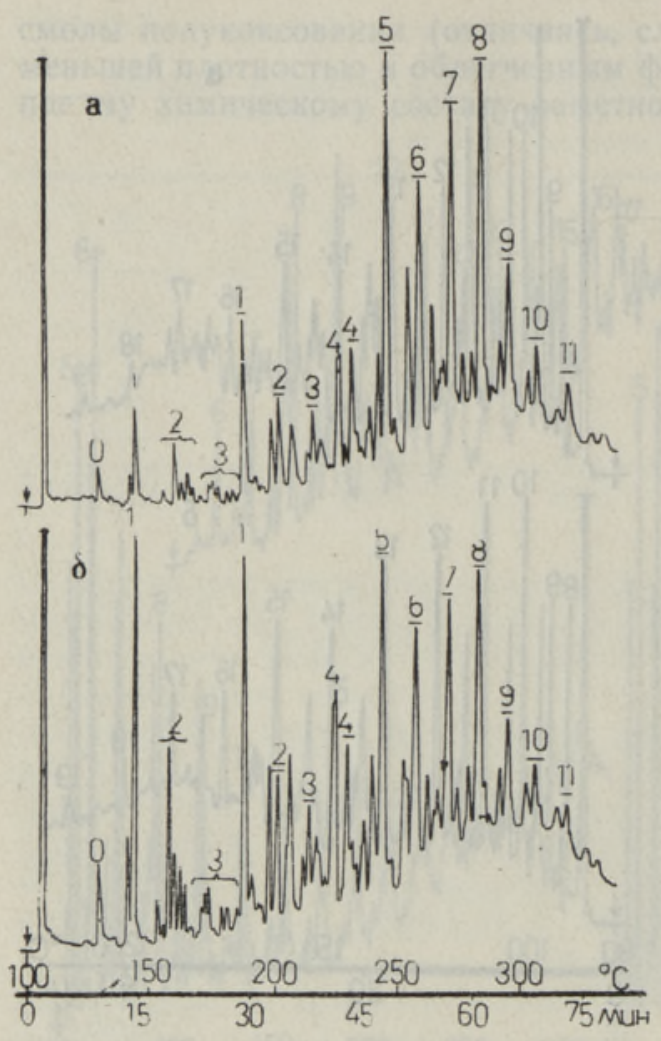

5-н-алкилпроизводных резорцина приходится в смоле битуминизации на соединения, боковая цепь которых содержит 5 и более атомов углерода (5-метилрезорцина здесь приблизительно в 2 раза меньше, чем в смоле полукоксования).

\section{Обсуждение результатов}

Для оценки химических сырьевых качеств смолы, образующейся при производстве термобитума, следует учитывать следующие основные особенности ее химического состава по сравнению со смолой полукоксования кукерсита:

Рнс. 4. Хроматограммы фенолов смол битуминизации $(a)$ и полукоксования (б) кукерсита.

$0-3$ - фенол и его алкилпроизводные; 4 - 1- и 2-нафтолы, $\underline{1-11}-$ 5-н-алкилпроизводные резорцина. Цифра указывает число атомов углерода в алкильных заместителях.

Колонка: $6 \%$ апиезона $L$ на хромосорбе $P$ (силанизир.), $6 \mu \times 3$ мм.

более высокое содержание олефинов, особенно ценных $\mathrm{C}_{9}-\mathrm{C}_{13}$

при одинаковом содержании фенолов в обычной и битуминизационной смоле в последней значительно меньше низкокипящих одноатомных фенолов, 5-метилрезорцина и незамещенных нафтолов; ведущую роль играют 5-н-алкилпроизводные резорцина с длинной (5-8 атомов углерода) боковой цепью;

очень мало нафталина и его простейших алкилпроизводных;

более высокое содержание моноциклических ароматических углеводородов, особенно низкокипящих.

В остальном смола битуминизации кукерсита по физическим свойствам и химическому составу подобна выкипающей примерно до $400^{\circ}$ части смолы полукоксования сланца при обычном режиме нагрева.

Если сравнить между собой смолу, образующуюся при битуминизации керогена, т. е. в условиях продолжительного нагревания при температуре не выше $400^{\circ}$, и смолу скоростного полукоксования сланца [ $\left.{ }^{8}\right]$, при котором температуру поднимали до конечной $\left(500-520^{\circ}\right)$ со скоростью $50^{\circ} /$ мин, то оказывается, что все перечисленные выше отличия смолы битуминизации от смолы полукоксования кукерсита в алюминиевой реторте относятся также и к смоле скоростного швелевания сланца. В случае битуминизационной смолы эти особенности выражены несколько сильнее.

Такое на первый взгляд странное сходство смол, полученных при совершенно разных режимах, можно объяснить тем, что в обоих случаях неблагоприятны условия для протекания вторичных процессов: при битуминизации - вследствие слишком низкой температуры, при скоростном 
полукоксовании - вследствие быстрой эвакуации продуктов из зоны высоких температур. При этом подразумеваются не только и не столько парофазные вторичные реакции, сколько процессы превращения первичных осколков керогена в жидко-твердой фазе. Следовательно, смолы битуминизации и скоростного полукоксования можно рассматривать как более первичные по сравнению со смолой швелевания сланца при стандартном режиме нагрева. На основе данных о химическом составе этих смол можно заключить, что низкокипящие монофенолы и первые члены ряда алкилпроизводных резорцина, нафталин и его низшие алкилпроизводные, отчасти также парафиновые углеводороды образуются преимущественно на более поздних стадиях термического разложения органической массы сланца и что они в основном не являются первичными осколками керогена. Напротив, $\boldsymbol{H}$-алкены, высшие 5- $н$-алкилпроизводные резорцина и низкокипящие моноциклические ароматические углеводороды следует считать генетически более тесно связанными со структурой исходного керогена.

\section{ЛИТЕРАТУРА}

1. Ш у льм а н А., Информ. бюлл. «Горючие сланцы», Таллин, № 4, 4 (1969).

2. К а ск К. А., Тр. Таллинск. политехн. ин-та, серия А, № 63, 51 (1955).

3. Термическая переработка сланца-кукерсита (под ред. М. Я. Губергрица). Таллин, 1966.

4. Барщевский М. М., Безмозгин Э. С., Ш а пиро Р. Н., Справочник по переработке горючих сланцев. Л., 1963.

5. К а ск К. А., Тр. Таллинск. политехн. ин-та, серия А, № 73, 23 (1956).

6. А а рн а А. Я., Л ип п а а Э. Т., Тр. Таллинск. политехн. ин-та, серия А, № 97 39 (1958).

7. К а сбе рг А. Ф., К лес м ен т И. Р., Химия твердого топлива, № 1, 107 (1969).

8. У ров К., К лесмент И., Э й зе н О., Изв. АН ЭССР, Хим. Геол., 23, 99 (1974)

Институт химии
Академии наук Эстонской СCP

Поступила в редакцию $22 / \mathrm{X} 1973$

Anne RANDUR, K. UROV, I. KLESMENT, O. EISEN

\section{KUKERSIIDIST TERMOBITUUMENI TOOTMISEL TEKKIVA OLI KOOSTIS}

Slantsõ põ̉levkivitöötlemiskombinaadis termobituumeni tootmisel kōrvalproduktina saadav õli sisaldab poolkoksistamisel saadud õliga vōrreldes rohkem sũsivesinikke (eriti monotsüklilisi aromaatseid ja küllastumatuid) ning resortsiini 5- $n$-alküülderivaate, mille kõrvalahelas on 5-8 süsinikuaatomit. Palju vähem on madalal temperatuuril keevaid ühealuselisi fenoole ja 5-metüülresortsiini ning naftaleeni ja tema lihtsamaid alküülderivaate; poolkoksistamisel moodustub nende ühendite põhiosa kerogeeni esialgsete frag mentide hilisema muundumise vältel.

\section{Anne RANDUR, K. UROV, I. KLESMENT, O. EISEN}

\section{COMPOSITION OF KUKERSITE-SHALE BITUMENIZATION OIL}

In comparison with the shale semi-coking oil, the oil obtained as by-product in the course of thermobitumen production contains a greater amount of hydrocarbons, especially monocyclic aromatic and n-alkenes, as well as 5-n-alkylresorcinols with a long (5-8 carbon atoms) side chain. The concentration of low-boiling monohydric phenols, 5methylresocinol, naphthalene and its simplest alkyl derivatives is considerably lower in the oil investigated than in the low-temperature carbonization oil, the bulk of these compounds in the latter appearing to be formed during further transformations of the kerogene primary fragments. 